\title{
ZAMAN VE FREKANS DÜZLEMİNDE YORULMA ÖMRÜ HESAPLAMA YÖNTEMLERİNİN SONLU ELEMANLAR YÖNTEMİ İLE İNCELENMESİ
}

\author{
Ömer Faruk DEMİRKAYA*, Kenan TÜFEKCi
}

Uludağ Üniversitesi Mühendislik Fakültesi Makine Müh. Böl. Bursa, Türkiye

\begin{tabular}{ll}
\hline Anahtar Kelimeler & Öz \\
\hline Rainflow Yöntemi, & Maruz kalınan titreşim nedeni ile meydana gelen yorulma hasarı ve ömrünü tespit \\
Dirlik Yöntemi, & etmek için zaman düzleminde ve frekans düzleminde hesaplama yapan yöntemler \\
Titreşim Kaynaklı Yorulma, & bulunmaktadır. Bu yöntemler sonlu eleman analizleri ile birlikte kullanılarak \\
Rastlantısal Titreşim, & mekanik tasarımın şekillendirilmesi sürecinde kritik rol oynamaktadır. Bu \\
Yorulma. & çalışmada zaman düzleminde yorulma hesaplayan Rainflow yöntemi ve frekans \\
& düzleminde yorulma hesaplayan Dirlik yöntemi sonlu elemanlar analizleri yardımı \\
& ile incelenmiş ve minimum yorulma ömrünü Dirlik metodunun verdiği görülmüştür. \\
& Herhangi bir test ile tasarım doğrulama imkânı bulunmadığında ve tasarım yalnızca \\
& sonlu elemanlar yöntemi ile değerlendirileceğinde, Dirlik metodu sonuçları referans \\
& alınarak yapılacak tasarımın en güvenli tasarımı vereceği için en avantajlı yöntem \\
& olduğu tespit edilmiştir.
\end{tabular}

\section{INVESTIGATION OF TIME AND FREQUENCY DOMAIN FATIGUE LIFE CALCULATION METHODS USING FINITE ELEMENT METHOD}

\begin{tabular}{ll}
\hline Keywords & Abstract \\
\hline $\begin{array}{l}\text { Rainflow Counting, } \\
\text { Dirlik Method, }\end{array}$ & $\begin{array}{l}\text { There are several vibration induced fatigue damage and life calculation methods in } \\
\text { time domain and frequency domain. These methods with the use of finite element } \\
\text { Vibration Fatigue, } \\
\text { Random Vibrations, }\end{array}$ \\
$\begin{array}{l}\text { Fatigue. } \\
\text { method play important role in mechanical design process. In this study, Rainflow }\end{array}$ \\
counting method and Dirlik counting method are investigated using finite element \\
method and it is found that Dirlik method gives minimum fatigue life. If there is not \\
an option to validate the design with tests and the only way to evaluate the design \\
is the finite element analysis, Dirlik method is advantageous because it gives the \\
safest design.
\end{tabular}

\section{Alıntı / Cite}

Demirkaya, Ö.F., Tüfekci, K., (2020). Zaman ve Frekans Düzleminde Yorulma Ömrü Hesaplama Yöntemlerinin Sonlu Elemanlar Yöntemi İle İncelenmesi, Mühendislik Bilimleri ve Tasarım Dergisi, 8(2), 467-478.

\begin{tabular}{l|l|l}
\hline Yazar Kimliği / Author ID (ORCID Number) & Makale Süreci / Article Process \\
\hline Ö.F. Demirkaya, 0000-0002-3278-9646 & Başvuru Tarihi / Submission Date & 10.01 .2020 \\
K. Tüfekci, 0000-0001-5358-1396 & Revizyon Tarihi / Revision Date & 23.04 .2020 \\
& Kabul Tarihi / Accepted Date & 14.05 .2020 \\
& Yayım Tarihi / Published Date & 25.06 .2020 \\
\hline
\end{tabular}

\section{Giriş (Introduction)}

Dinamik yüklere maruz bir yapıda malzemelerin kopma ve zaman zaman akma mukavemetinin altında gerilmelerde kırılması fenomeni 1800’lü yıllarda keşfedilmeye başlanmış ve yorulma ömrü kavramı ortaya çıkmıştır (Anonim, 1996). Kavramın ortaya çıkışından itibaren yapılan araştırmalar neticesinde yapıların yorulma ömrünü hesaplamak üzere çeşitli yöntemler geliştirilmiştir.

Yorulma ömrünü hesaplayan öncül yöntemler dönemin elverdiği koşullarda düzenli dinamik yükler altında yapıların davranışını incelerken 1900'lü yıllarda ölçüm ve bilgisayar teknolojilerinin hızla ilerlemesi ile düzensiz dinamik yüklere maruz yapıların yorulma ömrünün incelenmesine olanak sağlayan yöntemler geliştirilmeye başlanmıştır (Cooley ve Tukey, 1965, Piersol 1964, Bendat, 1964).

\footnotetext{
* ilgili yazar / Corresponding author: omerfarukdemirkaya92@gmail.com,+90-542-552-7111
} 
Düzensiz dinamik yüklere maruz bir yapının yorulma ömrünü inceleyen yöntemler zaman düzleminde ve frekans düzleminde olmak üzere ikiye ayrılmaktadır. Her iki yönteminde temeli, yapıda oluşan gerilmelerin içerisindeki gerilme aralığı ve çevrim sayılarının çevrim hesaplama yöntemleri ile bulunarak S-N/E-N (Gerilme-Çevrim Oranı/Gerinim-Çevrim Oranı) eğrileri ve kümülatif hasar kuramları yardımı ile yorulma ömrünün hesaplanmasına dayanmaktadır.

Zaman düzleminde yorulma ömrü inceleyen yöntemlerde, yapı üzerinde oluşan gerilmeler doğrudan zaman serisi olarak elde edilip bu veri üzerinden hesaplamalar yapılırken, frekans düzleminde yorulma ömrü inceleyen yöntemlerde oluşan gerilmeler frekans düzleminde güç spektral yoğunlukları cinsinden elde edilip bu veri üzerinden hesaplamalar yapılmaktadır (Şekil 1).

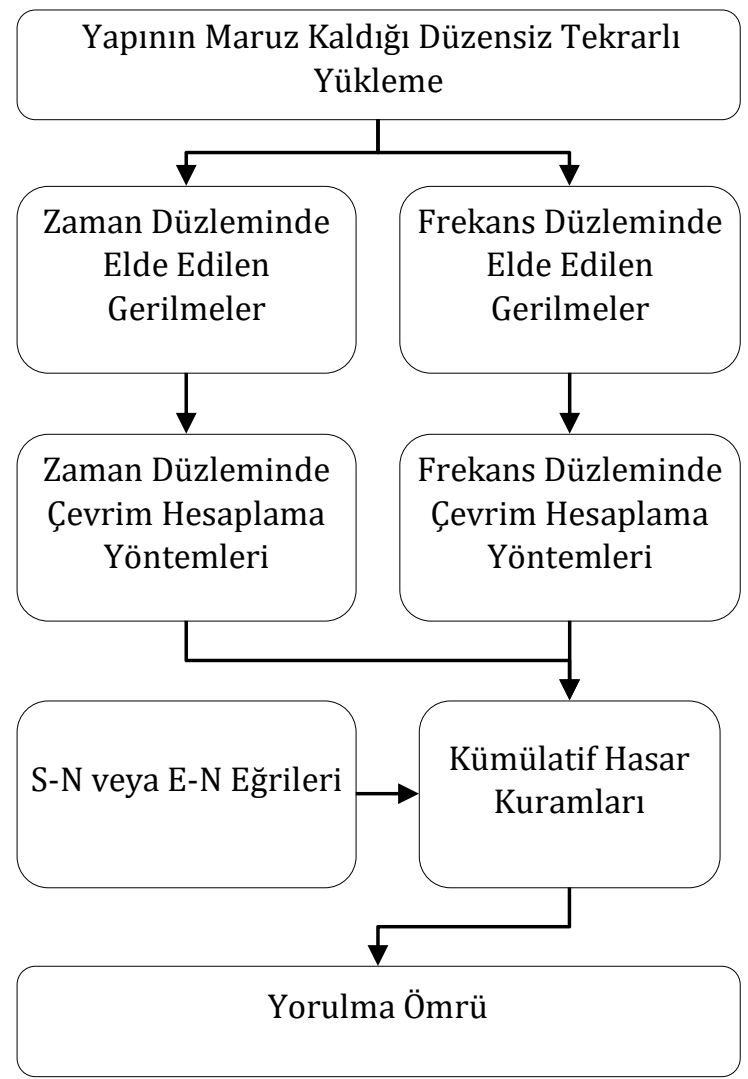

Şekil 1. Zaman ve frekans düzleminde yorulma ömrü hesaplama (Fatigue Life Calculation in time and frequency domain)

Günümüzde yaygın olarak zaman düzleminde çevrim hesaplama yöntemi olarak Rainflow metodu, frekans düzleminde çevrim hesaplama yöntemi olarak Dirlik metodu ve kümülatif hasar kuramı olarak Palmgren-Miner kuramı kullanılmaktadır.

Düzensiz dinamik yüklemeye maruz bir yapıda yorulma ömrünün bahsedilen yöntemler ile hesaplanabilmesi için oluşan gerilmelerin servis esnasında yapılan ölçümler veya sonlu elemanlar yöntemi yardımı ile elde edilmesi gerekmektedir.

Sonlu elemanlar yöntemi ile gerilmelerin elde edilerek yorulma ömrünün hesaplanması üretim öncesi risklerin belirlenerek gerekli tedbirlerin alınabilmesi için önem arz etmektedir. Sonlu eleman yöntemleri ile dinamik yüke maruz bir yapıda oluşan gerilmeleri zaman düzleminde belirlemek için direkt transient ve modal transient yöntemleri; frekans düzleminde belirlemek için rastlantısal titreşim yöntemi kullanılmaktadır. Transient ve modal transient yöntemlerinde yapının maruz kaldığı dinamik yük analize doğrudan zaman serisi olarak verilir ve çıktı olarak yine zaman serisi olarak gerilmeler elde edilir. Rastlantısal titreşim yönteminde analiz girdisi olarak yapının maruz kaldığı yük güç spektral yoğunluğu cinsinden verilerek yine çıktı olarak güç spektral yoğunluğu cinsinden gerilmeler elde edilir (Şekil 2). 


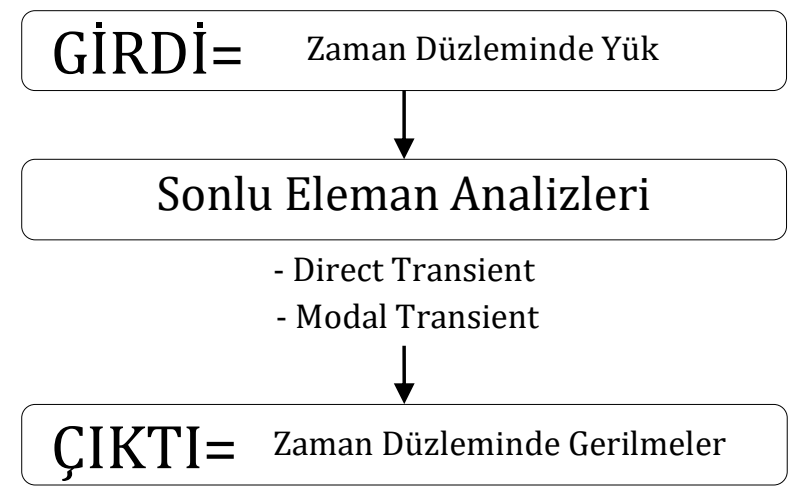

(a)

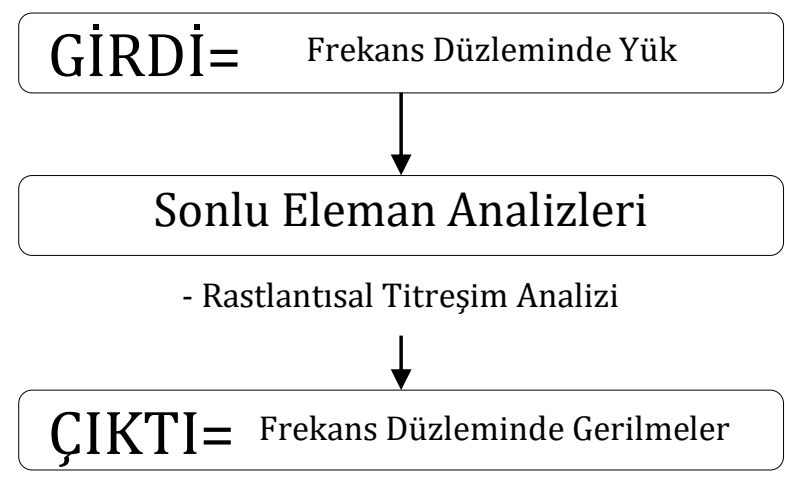

(b)

Şekil 2. Dinamik sonlu eleman analizleri (Dynamic finite element analysis)

Bu çalışmada belirlenen bir geometri için sonlu elemanlar yöntemleri kullanılarak zaman ve frekans düzleminde yorumla ömrü hesaplanıp farklı yöntemler için sonuçların karşılaştırılması yapılmıştır. Zaman düzleminde yapılan yorulma ömrü hesaplamaları için transient ve modal transient analizleri sonucu elde edilen gerilmeler Rainflow yöntemi ile incelenip, Palmgren-Miner kuramı ve S-N eğrileri kullanılarak ömür hesaplanmıștır. Frekans düzleminde yapılan yorulma ömrü hesaplamaları için rastlantısal titreşim analizi sonucu elde edilen gerilmeler Dirlik yöntemi ile incelenip, Palmgren-Miner kuramı ve S-N eğrileri kullanılarak ömür hesaplanmıștır.

\section{1. Çevrim Hesaplama Yöntemleri (Cycle Counting Methods)}

Zaman veya frekans düzleminde elde edilen gerilmelerin içerisindeki gerilme aralığı ve karşılık gelen çevrim miktarını hesaplayan yöntemlere çevrim hesaplama yöntemleri adı verilir. Çevrim hesaplama yöntemleri sabit gerilme aralığında yapllan yorulma testleri ile elde edilen S-N ve E-N eğrilerinin kullanılarak yorulma ömrü hesaplamasına olanak sağlar.

\subsection{Rainflow Çevrim Hesaplama Yöntemi (Rainflow Cycle Counging Method)}

Literatürde zaman düzleminde çevrim hesaplamak için Level-crossing counting, Range-pair counting, Reservoir counting ve Rainflow counting gibi çeşitli yöntemler bulunmaktadır (Marsh vd., 2016). Rainflow çevrim hesaplama yöntemi Japon bilim insanları Matsuishi ve Endo tafarından geliştirilmiş olup günümüzde en yaygın kullanılan çevrim hesaplama yöntemidir (Matsuishi ve Endo, 1968; Benasciutti vd., 2016).

Rainflow metodunun ortaya çıkmasının ardından üzerine yapılan çalışmalar devam etmiş ve 3 nokta Rainflow çevrim hesaplama, 4 nokta Rainflow çevrim hesaplama gibi çeşitli Rainflow algoritmaları oluşturulmuştur. ASTM E1049-85 (2017)'te çeşitli çevrim hesaplama yöntemi algoritmaları standart hale getirilmiş ve burada üç nokta Rainflow yöntemi standart olarak tanımlanmıştır.

Üç nokta Rainflow çevrim hesaplama yönteminde gerilme verisi yalnızca tepe ve vadilerden oluşacak ve mutlak değeri en büyük tepe veya vadi ile başlayacak şekilde düzenlenir. Başlangıç noktası için en büyük tepeden veya vadiden önceki veri kesilerek verinin sonuna eklenir. Düzenlemenin ardından sıra ile birbiri ardına gelen $S_{1}, S_{2}, S_{3}$ noktaları için $\Delta S_{1}=\left|S_{1}-S_{2}\right|, \Delta S_{2}=\left|S_{2}-S_{3}\right|$ olmak üzere; 
1. Eğer $\Delta \mathrm{S}_{1}>\Delta \mathrm{S}_{2}$ ise (Şekil 3.a); herhangi çevrim sayılmaz ve $\mathrm{S}_{1}, \mathrm{~S}_{2}, \mathrm{~S}_{3}$ kaydırılarak yeni çevrim aranır.

2. Eğer $\Delta S_{1} \leq \Delta S_{2}$ ise (Şekil 3.b); $\Delta S_{1}$ gerilme aralığında bir çevrim sayılır ve $S_{1}, S_{2}$ noktaları veriden çıkartılarak $\mathrm{S}_{1}$ 'den bir önceki nokta ile $\mathrm{S}_{3}$ birleştirilir (Şekil 3.c).

3. Yeni oluşan veri baștan başlanarak tekrar işlenir ve tüm veri bitene kadar bu işlem devam eder.

(a)

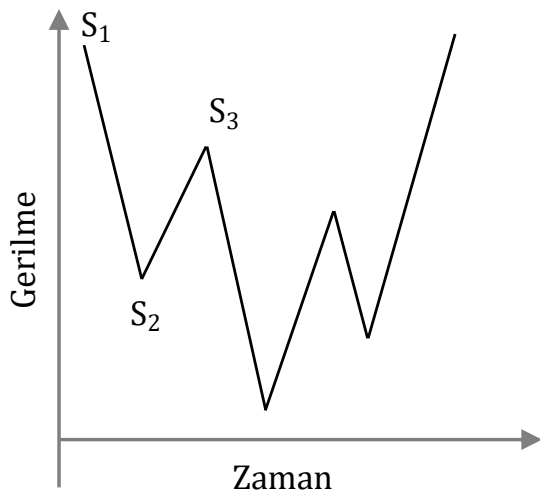

(b)

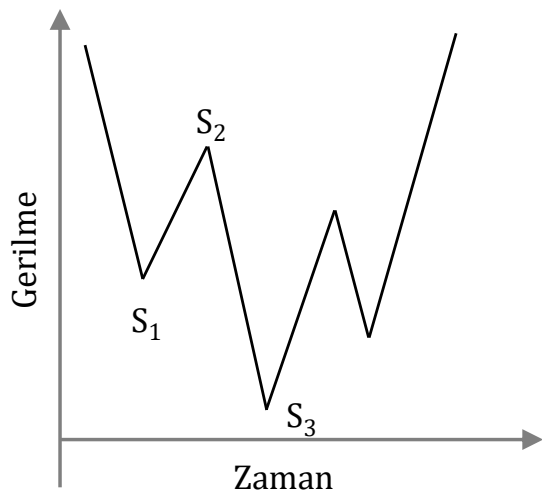

(c)

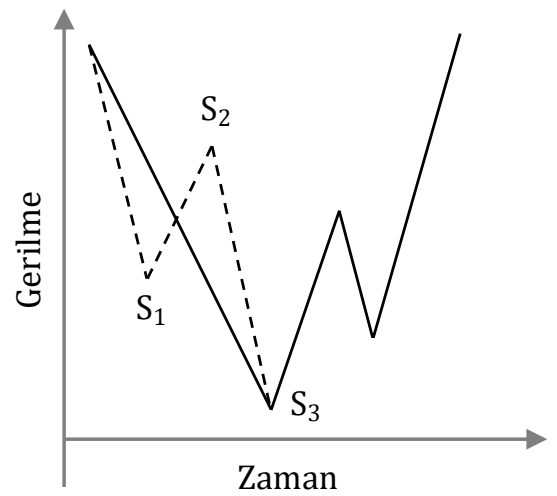

Şekil 3. $\Delta \mathbf{S}_{1}>\Delta \mathbf{S}_{2}$; çevrim yok (a), $\Delta \mathbf{S}_{1} \leq \Delta \mathbf{S}_{2}$; çevrim var (b), Çevrim sonrası yeni veri (c). ( $\Delta \mathbf{S}_{1}>\Delta \mathbf{S}_{2}$; no cycle (a), $\Delta \mathbf{S}_{1} \leq$ $\Delta \mathbf{S}_{2}$; cycle (b), new data after cycle(c).)

\subsection{Dirlik Çevrim Hesaplama Yöntemi (Dirlik Cycle Counting Method)}

Literatürde frekans düzleminde çevrim hesaplamak için Dirlik, Chaudhury\&Dover, Wirshicng, Hancock, Steinberg, Tuna, Narrow band gibi çeşitli yöntemler bulunmaktadır (Al-Bahkali vd., 2014). Dirlik çevrim hesaplama yöntemi testler ile en yakın sonucu veren yöntemdir (Sherratt vd., 2005).

Dirlik yönteminin temeli güç spektral yoğunluğu (PSD) cinsinden verilen gerilmeler için istatistiksel tanımlar kullanarak beklenen çevrim sayısının hesaplanmasına dayanmaktadır.

Dirlik yönteminde T süresi boyunca $S$ gerilme aralığındaki çevrim sayısı N(S); 


$$
\mathrm{N}(\mathrm{S})=\mathrm{E}[\mathrm{P}] \cdot \mathrm{T} \cdot \mathrm{p}(\mathrm{S})
$$

olarak verilir (Halfpenny, 1999). Burada E[P], PSD ile temsil edilen sinyal içerisindeki beklenen tepe noktası sayısı ve $\mathrm{p}(\mathrm{S})$ istatistik yoğunluk fonksiyonu olmak üzere;

$$
\begin{aligned}
& E[P]=\sqrt{\frac{m_{4}}{m_{2}}} \\
& p(S)=\frac{\frac{D_{1}}{Q} \cdot e^{\frac{-Z}{Q}}+\frac{D_{2} \cdot Z}{R^{2}} \cdot e^{\frac{-Z^{2}}{2 \cdot R^{2}}}+D_{3} \cdot Z \cdot e^{\frac{-Z^{2}}{2}}}{2 \cdot \sqrt{m_{0}}} \\
& \mathrm{D}_{1}=\frac{2 \cdot\left(\mathrm{x}_{\mathrm{m}}-\gamma^{2}\right)}{1+\gamma^{2}} \\
& \mathrm{D}_{2}=\frac{1-\gamma-\mathrm{D}_{1}+\mathrm{D}_{1}{ }^{2}}{1-\mathrm{R}} \\
& D_{3}=1-D_{1}-D_{2} \\
& \mathrm{Z}=\frac{\mathrm{S}}{2 \cdot \sqrt{\mathrm{m}_{0}}} \\
& \mathrm{Q}=\frac{1.25 \cdot\left(\gamma-\mathrm{D}_{3}-\mathrm{D}_{2} \cdot \mathrm{R}\right)}{\mathrm{D}_{1}} \\
& \mathrm{R}=\frac{\gamma-\mathrm{x}_{\mathrm{m}}-\mathrm{D}_{1}^{2}}{1-\gamma-\mathrm{D}_{1}+\mathrm{D}_{1}^{2}} \\
& \gamma=\frac{m_{2}}{\sqrt{m_{0} \cdot m_{4}}} \\
& \mathrm{x}_{\mathrm{m}}=\frac{\mathrm{m}_{1}}{\mathrm{~m}_{0}} \sqrt{\frac{\mathrm{m}_{2}}{\mathrm{~m}_{4}}}
\end{aligned}
$$

olarak verilir (Dirlik, 1985). Burada $m_{0}, m_{1}, m_{2} m_{3}$ ve $m_{4}$ frekans düzleminde gerilmeleri veren güç spektral yoğunluğunun alan momentleridir ve;

$$
m_{i}=\int_{0}^{\infty} \omega_{i} S(\omega) d \omega
$$

ile ifade edilir (Quigley ve Lee, 2012). Burada $\omega$ frekansı S( $\omega$ ) güç spektral yoğunluğu ifade eder.

\subsection{Kümülatif Hasar ve Palmgren-Miner Kuralı (Cumulative Damge and Palmgren-Miner Rule)}

Malzemelerin yorulma özelliği olarak verilen S-N eğrileri sabit bir gerilme aralığında malzemenin kırılacağı çevrim miktarını verir. Kümülatif hasar kuramları belirli çevrim sayılarında oluşan farklı gerilme aralıklarının toplam yorulma ömrüne etkisini inceler. İlk kümülatif hasar kuramı Palmgren (Palmgren, 1924) tarafından öne sürülmüş, Miner (Miner, 1945) tarafından matematiksel olarak ifade edilerek günümüzde Palmgren-Miner kümülatif hasar kuramı ortaya çıkmıștır. İlk kümülatif hasar kuramının ortaya çıkmasından bu yana birçok hasar kuramı öne sürülmesine karşın günümüzde halen Palmgren-Miner kuralı yaygın olarak kullanılmaktadır (Fatemi ve Yang, 1997).

Palmgren-Miner kuramı;

$$
\mathrm{D}=\sum \frac{\mathrm{n}_{\mathrm{i}}}{\mathrm{N}_{\mathrm{fi}}}
$$


olarak ifade edilir. Burada $n_{i}$ maruz kalınan $S_{i}$ gerilme aralığındaki çevrim sayısını; $N_{f i} S-N$ eğrisinde $S_{i}$ gerilme aralığına karşılık gelen çevrim miktarını ifade eder. Palmgren-Miner kuramına göre $\mathrm{D}=1$ olduğunda hasar meydana gelmektedir.

\subsection{Sonlu Eleman Yöntemleri (Finite Element Methods)}

Sonlu eleman yöntemleri titreşime maruz bir yapıda oluşan gerilmelerin hesaplanması için kullanılır. Zaman düzleminde dinamik sonlu eleman yöntemleri kullanılırken, frekans düzleminde rastlantısal titreşim yöntemi kullanilır.

\subsubsection{Zaman Düzleminde Sonlu Eleman Yöntemleri (Finite Element Method in Time Domain)}

\section{- Direkt Transient Analiz (Direct Transient Analysis)}

Lineer dinamik problemler için bir yapının sonlu eleman formülasyonu;

$$
[\mathrm{M}]\{\ddot{\mathrm{u}}(\mathrm{t})\}+[\mathrm{C}]\{\dot{\mathrm{u}}(\mathrm{t})\}+[\mathrm{K}]\{\mathrm{u}(\mathrm{t})\}=\{\mathrm{F}(\mathrm{t})\}
$$

ile verilir. Burada [M] kütle matrisi, [C] sönüm matrisi, $[\mathrm{K}]$ rijitlik matrisi, $\{\mathrm{u}(\mathrm{t})\}$ nodal deplasman vektörü, $\{\dot{\mathrm{u}}(\mathrm{t})\}$ nodal hız vektörü, $\{\ddot{\mathrm{u}}(\mathrm{t})\}$ nodal ivme vektörü ve $\{\mathrm{F}(\mathrm{t})\}$ kuvvet vektörünü ifade eder.

Direkt transient analiz yönteminde implisit zaman integrasyonu ile elde edilen birbirine bağıml denklem takımları lineer cebir yöntemleri ile iteratif bir şekilde çözülerek sonuç elde edilir.

\section{- Modal Transient Analiz (Modal Trainsient Analysis)}

Eşitlik 14'te görülen $\{\mathrm{u}(\mathrm{t})\}$ ve $\{\mathrm{F}(\mathrm{t})\}$ için, $\left\{\varnothing_{\mathrm{i}}\right\} \bmod$ şekil vektörü ve $\mathrm{y}_{\mathrm{i}}$ modal koordinatlar olmak üzere;

$$
\begin{aligned}
& \{\mathrm{u}(\mathrm{t})\}=\sum_{\mathrm{i}=1}^{\mathrm{n}}\left\{\varnothing_{\mathrm{i}}\right\} \mathrm{y}_{\mathrm{i}} \\
& \mathrm{f}_{\mathrm{i}}=\left\{\varnothing_{\mathrm{i}}\right\}^{\mathrm{T}}\{\mathrm{F}(\mathrm{t})\}
\end{aligned}
$$

tanımları yapılabilir.

Bu tanımlardan yola çıkarak Eşitlik 14;

$$
\ddot{y}_{i}+2 \omega_{i} \xi_{i} \dot{y}_{i}+\omega_{i}^{2} y_{i}=f_{i}
$$

șeklinde yazılabilir. Burada $\omega_{\mathrm{i}}$ ve $\xi_{\mathrm{i}}$ i. mod için frekans ve sönüm katsayısını ifade eder. Eșitlik 17 çözülüp Eșitlik 15 ile tersine dönüşüm yapıldığında $\{\mathrm{u}(\mathrm{t})\}$ elde edilir. Eşitlik 17 birbirinden bağımsız denklemlerden oluşmaktadır ve bu nedenle iteratif bir çözüme gerek duyulmaz. Böylece direkt transient yöntemlerine göre daha hızlı bir çözüm elde edilmiş olur (Horas vd., 2016). Modal transient yönteminin uygulanabilmesi için gerekli mod şekilleri $\left\{\emptyset_{i}\right\}$ ve mod frekansları $\omega_{\mathrm{i}}$ modal analiz yapılarak elde edilir.

\subsubsection{Frekans Düzleminde Sonlu Eleman Yöntemi (Finite Element Method in Frequency Domain)}

\section{- Rastlantısal Titreşim Yöntemi (Random Vibrations Method)}

Rastlantısal titreşimler teorisine göre zaman düzlemindeki Gauss dağllımına sahip durağan rastsal bir sinyal güç spektral yoğunluğu ile frekans düzleminde ifade edilebilir. Güç spektral yoğunluğu sinyalin güç içeriğinin frekansa bağlı bir ölçüsüdür ve birimi ifade edilen sinyalin birimine göre $\frac{\text { Birim }^{2}}{\mathrm{~Hz}}$ ile verilir.

Güç spektral yoğunluğu S( $\omega)$, FFT bir sinyalin Fourier Transformu ve $\Delta \omega$ sinyal çözünürlüğü olmak üzere;

$$
\mathrm{S}(\omega)=\frac{|F F T|^{2}}{\Delta \omega}
$$


ile elde edilir (Bishop ve Sherratt, 2000).

Güç spektral yoğunluğu sinyalin istatistiksel özelliklerini barındırır, örneğin spektrum altında kalan sinyalin ortalama karekök değerini verir;

$$
R M S=\sqrt{\int_{\omega_{1}}^{\omega_{2}} S(\omega) \mathrm{d} \omega}
$$

Burada RMS sinyalin ortalama karekök değerini ve S( $\omega)$ güç spektral yoğunluğunu ifade eder.

Hareket denklemi Eşitlik 14 ile ifade edilebilen tek serbestlik derecesine sahip lineer bir sistem frekans düzleminde için girdi ve çıktı ilişkisi frekans cevap fonksiyonu ile ifade edilebilir (Şekil 4).

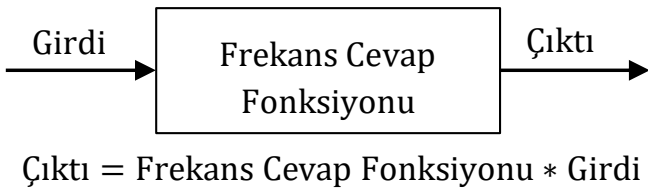

Şekil 4. Lineer sistemlerde girdi ile çıktı arasındaki ilişki (Input-output relationship of linear systems)

Bir yapının maruz kaldığı titreşim(deplasman, hız, ivme, kuvvet) güç spektral yoğunluğu cinsinden bilindiğinde bu titreşime karşı verilen cevap;

$$
S_{y y}(\omega)=|H(\omega)|^{2} S_{x x}(\omega)
$$

ile ifade edilir (Mršnik vd., 2016). Burada $S_{y y}(\omega)$ güç spektral yoğunluğu cinsinden çıktl, $S_{x x}(\omega)$ güç spektral yoğunluğu cinsinden girdiyi ve $\mathrm{H}(\omega)$ frekans cevap fonksiyonunu ifade eder.

Sonlu eleman yönteminde yapının frekans cevap fonksiyonu modal analiz yardımı ile belirlenir ve yapıya güç spektral yoğunluğu cinsinden deplasman, hız veya ivme uygulanarak yine güç spektral yoğunluğu cinsinden gerilmeler elde edilir. Elde edilen bu gerilmeler daha sonra yorulma ömrü hesaplamak üzere frekans düzleminde çevrim hesaplama yöntemlerine girdi oluşturur.

\section{Materyal ve Yöntem (Materials and Method)}

Bu çalışmada Şekil 5’te gösterilen AL6061-T6 malzemeden yapılmış; çentikli kiriş geometrisi için yorulma ömrü zaman düzleminde direkt transient ve modal transient sonlu eleman yöntemleri ve Rainflow çevrim hesaplama yöntemi ile, frekans düzleminde rastlantısal titreşim sonlu eleman yöntemi ve Dirlik çevrim hesaplama yöntemi ile elde edilip sonuçlar kıyaslanarak yöntemlerin avantaj ve dezavantajları incelenmiştir.

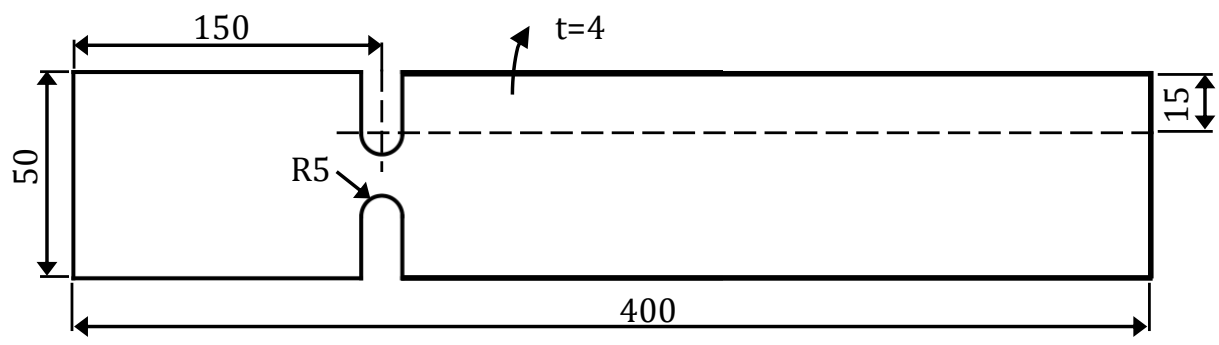

Şekil 5. Analizi yapılacak geometrinin ölçüleri (Dimensions of analysis geometry)

\subsection{Sonlu Eleman Modeli (Finite Element Model)}

Sonlu elemanlar analizleri ANSYS yazılımında, yorulma analizleri nCode Designlife yazılımında gerçekleştirilmiştir. Şekil 6'da sonlu elemanlar modeli görülmektedir. 
Sonlu eleman modeli lineer katı elemanlar ile hazırlanmıștır. Model 2224 adet eleman ve 3615 dügüm noktasından oluşmaktadır. Çentik bölgesinde $1 \mathrm{~mm}$ eleman boyutu kullanılmıştır. Model Şekil 6'da yeşil ile görülen yerden sabitlenmiştir.
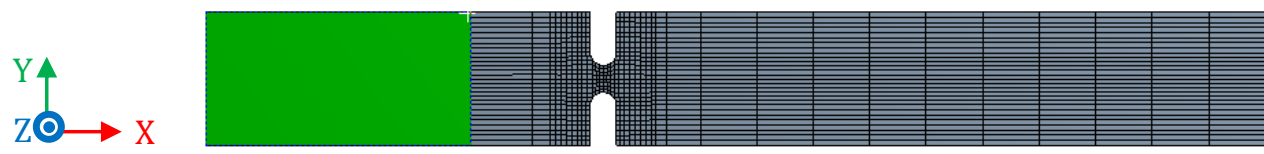

Şekil 6. Sonlu elemanlar modeli (The finite element model)

Sonlu eleman analizlerinde AL6061-T6 malzeme için E elastikiyet modülü, $\rho$ yoğunluk ve $v$ Poisson oranı olmak üzere;

$$
\begin{gathered}
\mathrm{E}=71000 \mathrm{MPa} \\
\rho=2.77 e^{-6} \mathrm{~kg} / \mathrm{mm}^{3} \\
v=0.33
\end{gathered}
$$

olarak tanımlanmıştır.

Yorulma ömrü hesabı için kullanılan S-N eğrileri MIL-HDBK-5J (2013)’ye göre oluşturulmuştur.

\subsection{Zaman ve Frekans Düzleminde İvme Verisi (Acceleration Data in Time and Frequency Domain)}

Zaman düzleminde yapılacak olan sonlu eleman analizlerinde uygulanmak üzere oluşturulan beyaz gürültü ivme verisi Şekil 7'de gösterilmiştir. Beyaz gürültü Gauss dağılımında sahip durağan rastlantısal olduğu için rastlantısal titreșim yönteminin kullanılabilmesine olanak sağlar. Oluşturulan ivmenin istatistik verileri Tablo 1'de verilmiştir.

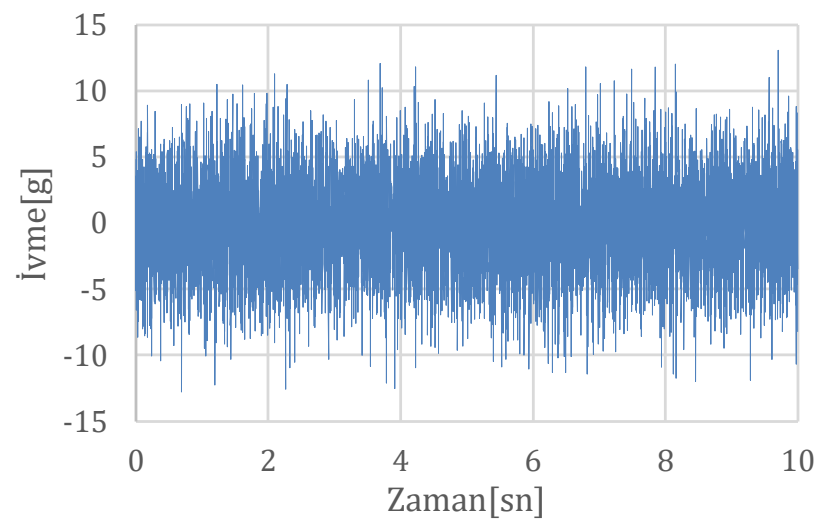

Şekil 7. Sonlu eleman analizlerinde kullanılmak üzere üretilen ivme verisi (Acceleration data used for finite element analyses)

Tablo 1. İvme verisinin istatistikleri (Statistics of acceleration data)

\begin{tabular}{|c|c|c|c|c|}
\hline grms & Ortalama & Standart Sapma & Maksimum & Minimum \\
\hline 3.839 & -0.16771 & 3.837 & 13.08 & -12.80 \\
\hline
\end{tabular}

Şekil 8'de ivme verisinin olasılık dağılımı görülmektedir. Gauss dağılımına sahip bir veri için Kurtosis 3, Skewness 0’dır (Palmieri ve ark. 2016). Buna göre ivme verisinin normal dağılıma yakın olduğu söylenebilir. 


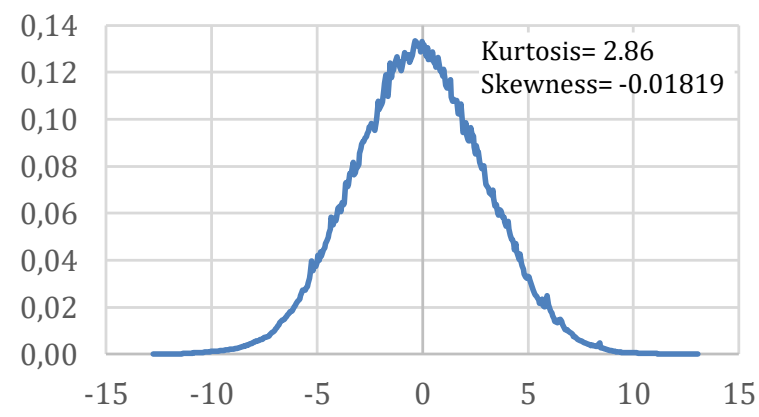

Şekil 8. İvme verisinin olasılık dağılımı (Propability distribution of acceleration data)

Beyaz gürültüde güç farklı frekanslara eşit şekilde dağıldığı için güç spektral yoğunluğu sabit bir çizgi şeklindedir. Şekil 9'da, Şekil 7'de gösterilen zamana bağlı ivmenin teorik ve numerik olarak hesaplanan güç spektral yoğunluğu verisi gözükmektedir.

Güç spektrum yoğunluğu altında kalan alanın karekökü temsil edilen verinin RMS değerini verir. Tablo 2‘de güç spektral yoğunluğu RMS değerleri verilmiștir.

Tablo 2. Güç spektral yoğunluğu RMS değerleri (RMS values of power spectral densities)

\begin{tabular}{|c|c|}
\hline & grms $_{\text {rms }}$ \\
\hline Numerik & 3.832 \\
\hline Teorik & 3.840 \\
\hline
\end{tabular}

Zaman düzleminde direkt transient ve modal transient analizleri yapılmıştır. Her iki analizde de girdi olarak zaman düzleminde Șekil 7'de gösterilen ivme verisi z-ekseninde uygulanmıştır.

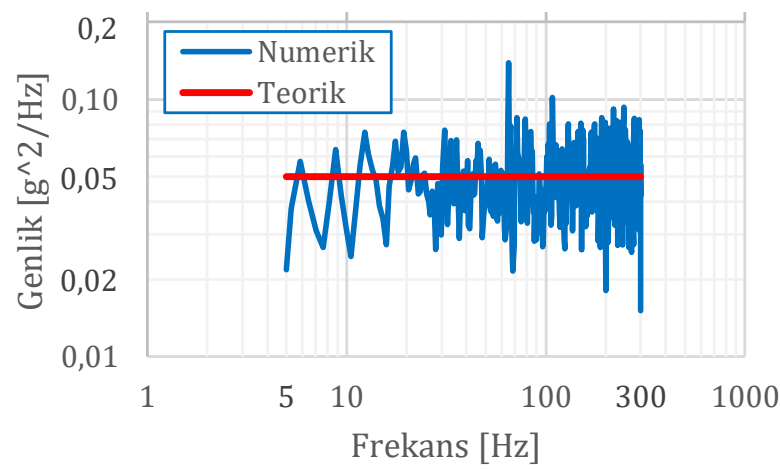

Şekil 9. İvme verisinin güç spektral yoğunluğu (Power spectral density of acceleration data)

Frekans düzleminde rastlantısal titreşim analizi yapılmıştır. Analizde girdi olarak Şekil 9'da verilen numerik olarak hesaplanmış güç spektral yoğunluğu verisi z-ekseninde uygulanmıştır.

\section{Bulgular (Results)}

\subsection{Zaman Düzleminde Yorulma Ömrü (Fatigue Life in Time Domain)}

Şekil 10 (a) ve (b)'de transient ve modal Transient analizleri sonucu çentik bölgesinde 10 sn içerisinde oluşan maksimum eşdeğer gerilmeler görülmektedir. Oluşan gerilmeler incelendiğinde gerilme kontürü benzer görünürken maksimum değerler arasında 7.26 MPa'llk bir fark görülmektedir.

Şekil 11 (a) ve (b)'de transient ve modal transient analizleri sonucu elde edilen gerilmeler kullanılarak Rainflow yöntemi ile yapılan yorulma analizi sonuçları görülmektedir. Sonuçlar incelendiğinde bulunan ömür arasında $2.263 \mathrm{e}^{8}$ tekrarlık bir fark görülmektedir. 


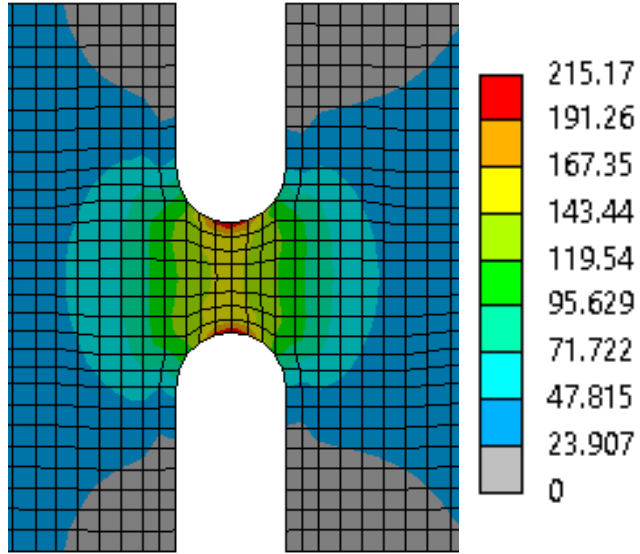

(a)

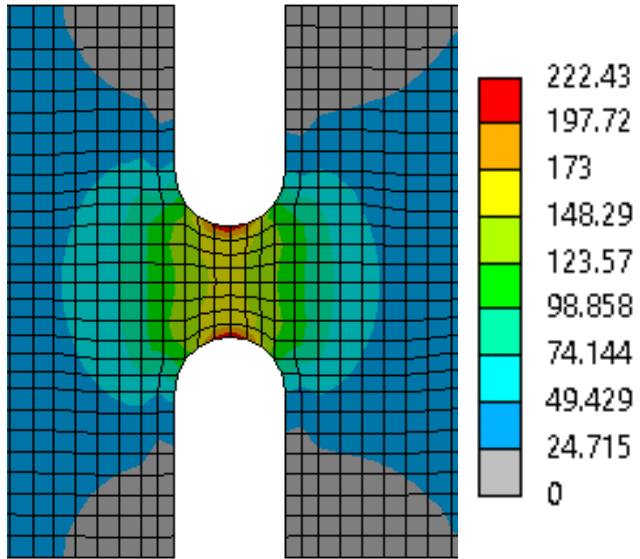

(b)

Şekil 10. Zaman düzleminde yapılan analiz sonucu oluşan eşdeğer gerilmeler (MPa). Modal transient analiz (a), Transient analiz (b). (Equivalent stress in time domain (MPa). Modal transient analysis (a), Transient analysis (b))

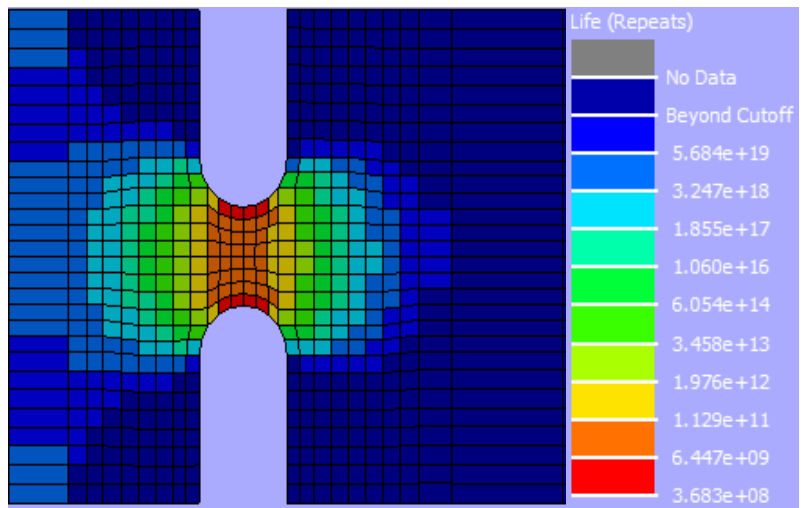

(a)

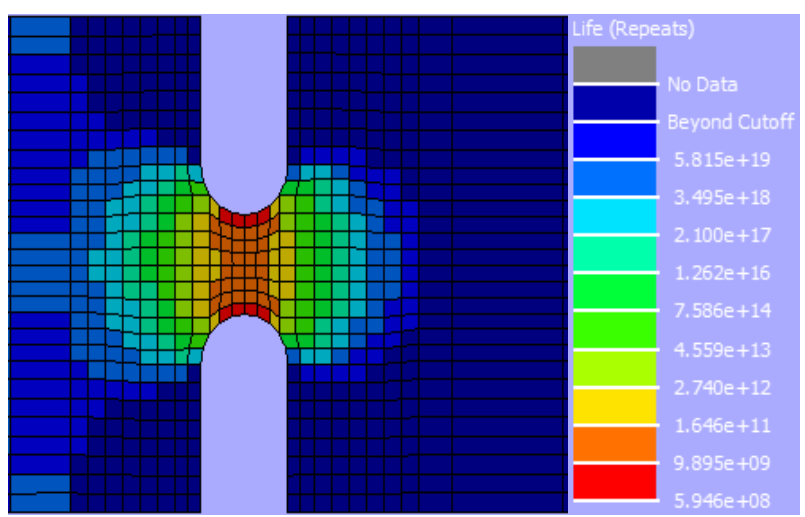

(b)

Şekil 11. Zaman düzleminde yapılan analiz sonucu oluşan yorulma ömrü (Tekrar). Modal transient analiz (a), Transient analiz (b). (Fatigue life in time domain. (Repeats). Modal transient analysis (a), Transient analysis (b)) 


\subsection{Frekans Düzleminde Yorulma Ömrü (Fatige Life in Frequency Domain)}

Şekil 12'de rastlantısal titreşim analizi sonucu elde edilen $3 \sigma$ standart sapmada oluşan gerilmeler görülmektedir. Sonuçlar incelendiğin maksimum gerilmenin 230.61 MPa olduğu görülmektedir.

Şekil 13'te rastlantısal titreşim analizi sonucu elde edilen gerilmeler kullanılarak Dirlik yöntemi ile yapılan yorulma analizi sonuçları görülmektedir. Sonuçlar incelendiğinde minimum yorulma ömrünün $1.019 \mathrm{e}^{7}$ olduğu görülmektedir.

\section{Tartışma ve Sonuçlar (Discussion and Conclusion)}

Tablo 3'de zaman ve frekans düzleminde yapılan sonlu elemanlar analizleri sonucu elde edilen maksimum gerilmeler, minimum yorulma süreleri, her bir analizin çözüm süresi gösterilmiştir. Buna göre sonlu elemanlar analizleri sonucu oluşan gerilmeler tüm analizler için birbirine yakın gözükürken yorulma ömürleri arasında belirgin farklar gözükmektedir. En düşük yorulma ömrünün Dirlik yöntemi ile elde edildiği görülmektedir. Çözüm süreleri incelendiğinde en uzun çözüm süresinin transient analizde olduğu görülmektedir.

Bu bulgulara göre eğer bir mekanik yapının yorulma ömrü yalnızca sonlu elemanlar analizleri kullanılarak değerlendirilecek ise en güvenli tasarımı oluşturmak için minimum yorulma ömrünü veren Dirlik metodunun kullanılması gerekmektedir. Öte yandan așırı güvenli tasarımın maliyetleri göz önünde bulundurulduğunda nihai tasarımın testler ile doğrulanarak oluşturulması önem arz etmektedir.

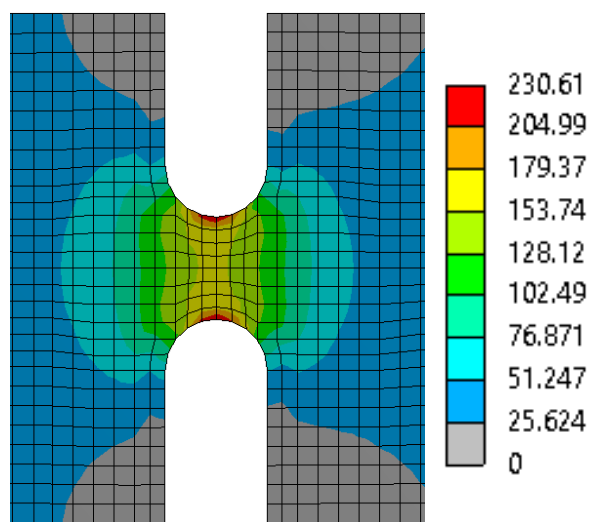

Şekil 12. Frekans düzleminde yapılan analiz sonucu oluşan eșdeğer gerilmeler (MPa) (Equivalent stress in frequency domain $(\mathrm{MPa}))$

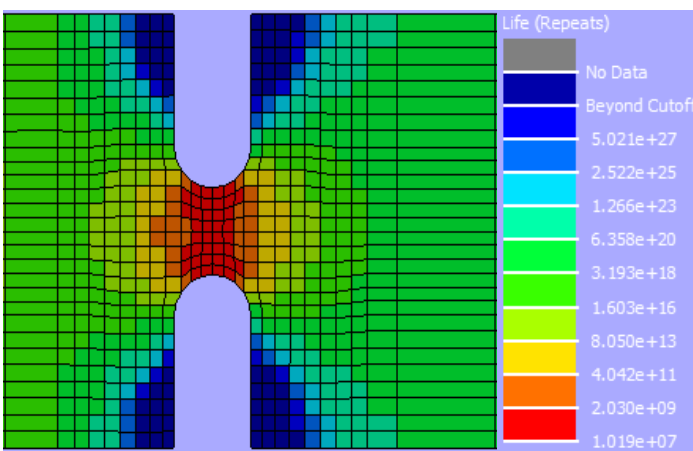

Şekil 13. Frekans düzleminde yapılan analiz sonucu oluşan yorulma ömrü (Tekrar). (Fatigue life in frequency domain (Repeats)) 
Tablo 3. Yapılan analiz sonuçlarının karşılaştırılması (Comparison of results)

\begin{tabular}{|c|c|c|c|}
\hline & $\begin{array}{c}\text { Maksimum Eşdeğer } \\
\text { Gerilme(MPa) }\end{array}$ & $\begin{array}{c}\text { Minimum Yorulma } \\
\text { Ömrü(Tekrar) }\end{array}$ & $\begin{array}{c}\text { Çözüm Süresi } \\
\text { (Dakika) }\end{array}$ \\
\hline $\begin{array}{c}\text { Modal Transient analiz } \\
\text { ve Rainflow yöntemi }\end{array}$ & 215.17 & $3.683 \mathrm{e}^{8}$ & 65 \\
\hline $\begin{array}{c}\text { Transient analiz ve } \\
\text { Rainflow yöntemi }\end{array}$ & 222.43 & $5.946 \mathrm{e}^{8}$ & 0.2 \\
\hline $\begin{array}{c}\text { Rastlantısal Titreşim } \\
\text { analizi ve Dirlik yöntemi }\end{array}$ & 230.61 & $1.019 \mathrm{e}^{7}$ & 65 \\
\hline
\end{tabular}

\section{Çıkar Çatışması (Conflict of Interest)}

Yazarlar tarafından herhangi bir çıkar çatışması beyan edilmemiştir. No conflict of interest was declared by the authors.

\section{Kaynaklar (References)}

Al-Bahkali, E., Elkenani, H., Souli, M., 2014. Fatigue life estimate of landing Gear's leg using modal analysis, International Journal of Multiphysics, 8 (2), 231-244.

Anonim, 1996. ASM Handbook Fatigue and Fracture Volume 19, ASM International, U.S.

ASTM E1049-85, 2017. Standard Practices for Cycle Counting in Fatigue Analysis, ASTM International, West Conshohocken, PA.

Benasciutti, D., Sherratt, F., Cristofori, A., 2016. Recent developments in frequency domain multi-axial fatigue analysis, International Journal of Fatigue, 91 (2), 397-413.

Bendat, J.S., 1964. Probability Functions for Random Responses: Prediction of Peaks, Fatigue Damage, and Catastrophic Failures. NASA Contractor Report, U.S.

Bishop, N., Sherratt, F., 2000. Finite Element Based Fatigue Calculations, NAFEMS, U.K.

Cooley, J. W., Tukey, J.W, 1965. An Algorithm for the Machine Calculation of Complex Fourier Series, Mathematics of Computation, 19 (90), 297-301.

Dirlik, T., 1985. Application of computers to fatigue analysis, Doktora Tezi, University of Warwick.

Fatemi, A., Yang., L., 1998. Cumulative fatigue damage theories: a survey of state of the art for homogenious materials, International Journal of Fatigue, 20 (1), 9-34.

Halfpenny, A., 1999. Key Engineering Materials, 167, 401-410.

Horas, C.S., Correia, J.A.F.O., De Jesus, A.M.P., Calçada, R., Aenlle, M.L., Kripakaran, P., Pelayo, F., Fenandez-Canteli, A., 2016. Application of modal superposition technique in the fatigue analysis using local approaches, Procedia Engineering, 160, 4552.

Marsh G., Wignall., Thies P.R., Barltrop N., Incecik A., Venugopal V., Johanning., 2016. Review and application of Rainflow residue processing techniques for accurate fatigue damage estimation, International Journal of Fatigue, 82 (3), 757-765.

Matsuishi M., Endo T., 1968. Fatigue of metals subject to varying stress, Proc. Kyushu Branch of Japan Society of Mechanical Engineers, 37-40.

MIL-HDBK-5J, 2003. Metallic Materials And Elements for Aerospace Vehicle Structures, Department of Defense Handbook, U.S.

Miner, M.A., 1945. Cumulative damage in fatigue, Journal of Applied Mechanics, 12, 159-164.

Mršnik, M., Slavič, J., Boltežar, M., 2016. Frequency-domain methods for a vibration-fatigue-life estimation - Application to real data, International Journal of Fatigue, 47, 8-17.

Palmgren, A., 1924, Die lebensdauer von kugellagern, VDI-Zeitschrift, 68, 339-341.

Palmieri, M., Česnik, M., Cianetti, F., Slavič., J Boltežar, M., 2017. Non-Gaussianity and non-stationarity in vibration fatigue, International Journal of Fatigue, 97, 9-19.

Piersol, G. A., 1964. The Measurement and Interpretation of Ordinary Power Spectra for Vibration Problems, NASA Contractor Report, U.S.

Quigley, J., Lee, Y., 2012. Assessing Dirlik's Fatigue Damage Estimation Method for Automotive Applications, SAE International Journal of Passenger Cars - Mechanical Systems, 5(2), 911-920.

Sherratt, F., Bishop, N.W.M., Dirlik T., 2005. Predicting fatigue life from frequency domain data, Enginnering Integrity, 8, 12-16. 